\title{
AN INTEGRATED APPROACH TO TEACHING AND LEARNING LOGISTICS: A CASE STUDY
}

\author{
JACOBUS N. CRONJÉ \\ jacobus.cronje@nwu.ac.za \\ Department of Transport Economics and Logistics Management \\ North-West University (Mafikeng Campus) South Africa
}

\begin{abstract}
Business managers and students often criticise university teaching for not addressing real-life problems. Furthermore, professors are dissatisfied with the research capabilities of postgraduate students. This paper advocates an integrated approach to teaching and learning based on the features of project-based learning aimed at enhancing the practical and research skills of undergraduate students in Logistics. A case study is presented where third-year students were engaged in a real-life project in collaboration with industry, exposing them to collaborative learning, questionnaire design, surveys, analysing and evaluating results, literature review and report writing. The project was carried out in phases where students were assessed after each phase. The paper analyses the assessment of students and their perception of the value of the project. It is concluded that an integrated teaching and learning approach will increase students' interest in the subject, understanding of theoretical concepts, research skills, business skills and life skills.
\end{abstract}

\section{INTRODUCTION}

This paper reports on an integrated approach to the teaching and learning of Logistics aimed at enhancing the research skills, business skills (applying theory to practice) and professional or life skills of undergraduate students. The approach involves practical real-life projects in collaboration with the industry and is based on many of the features of projectbased learning (PBL) as a teaching strategy. A case study is presented of a pilot project where 42 Logistics Management students in their third (and final) year of undergraduate study at the North-West University (Mafikeng Campus) in South Africa were engaged in an external customer service audit at a major retailer in the Fast Moving Consumer Goods (FMCG) industry.

Increasing emphasis is placed on research in higher education worldwide. The latest policy with regard to higher education in South Africa, as contained in the Higher Education Qualifications Framework (HEQF) which forms an integral part of the National Qualifications Framework (NOF), places a mandatory requirement of at least 30 credits 
supervised research on all Bachelor's Honours degrees (Republic of South Africa, 2007). This requirement is based on one of the objectives of the HEQF, namely to 'enhance the development of a vibrant, high quality research system' (Republic of South Africa, 2007:10.) This mandatory requirement places an additional workload on academic lecturers since the average undergraduate student has little or no exposure to research. To facilitate the task of lecturers in supervising the research projects of honours students it is essential that undergraduate students be exposed to research to some extent before they engage in Bachelor's Honours studies. In this regard, Van Hoek (2001) and Rutledge and Maehler (2003) contend that academic staff is concerned about the poor research capabilities of students. Informal discussions with professors in various disciplines confirm this concern.

A further and perhaps more serious problem is that academic teaching is often criticised by business practitioners and students because it lacks relevance, focuses too much on theory and does not address practical, real-life problems sufficiently (Alvarstein \& Johannesen, 2001; Van Hoek, 2001; Hanney, 2005; Garcia, 2006). Gattorna, (2009:47) expresses a serious concern about the capability of business managers, particularly in logistics and supply chain management. He partly blames educational institutions who teach the 'same old stuff' to their students. One of the objectives of the HEQF is to 'facilitate the education of graduates who will contribute to the social, cultural and economic development of South Africa and participate successfully in the global economy and knowledge society' (Republic of South Africa, 2007:10). It is therefore imperative that higher education institutions not only address academic theories, but also focus on addressing real-life problems.

Another set of skills that need to be developed is what the author terms life skills and which are referred to by other authors as professional skills (Van Hoek, 2001; Garcia, 2006). These skills are encapsulated in the NQF as being critical cross field outcomes (CCFOs). The South African Qualifications Authority (SAQA) stipulates that the learning outcomes of all South African qualifications should include critical cross field or generic skills to promote lifelong learning (Republic of South Africa, 1998; Bender, Daniels, Lazarus, Naude \& Sattar, 2006; Republic of South Africa, 2007).

Lee, McGuiggan and Holland (2010:569) argue that industry, government and academic institutions should employ various teaching and learning strategies to meet the needs of a 'learning economy'. The authors cite Boles, Beck and Hargreaves (2005) who suggest that higher education institutions should reflect the changing needs of society.

The theoretical framework for the integrated teaching and learning approach suggested in this paper is based on constructivist teaching strategies with due consideration of the various types of skills requirements discussed above. Constructivist approaches are learner centred and focus on learning by doing and active student participation to enhance students' life 
skills (Gülbahar \& Tinmaz, 2006; Hallinger \& Lu, 2011). Case-based learning, problem-based learning and project-based learning (PBL) are typical teaching strategies that are grounded in constructivism and developed mainly as a result of Dewey's proposition that 'experience is the basis of education' (Dewey, 1933 as cited by Lee et al., 2010:569; Hunaiti, Grimaldi, Goven, Mootanah \& Martin, 2010:196). These three strategies are briefly discussed below.

Case-based learning contains an element of problem solving which the student is likely to come across in the workplace and provides a practical setting where certain life skills can be developed. (Gudmundsson \& Nijhuis, 2001; Van Hoek, 2001). However, it does not involve real-life projects and therefore does not address real-life problem solving to the same extent as projects in collaboration with industry.

Hallinger and Lu (2011) conclude that problem-based learning is characterised by a problem (as opposed to a theory) that students are likely to encounter in the workplace, a curriculum that is organised around problems rather than subject disciplines, students who are responsible for managing their own learning, collaborative learning in small groups as opposed to formal lectures and simulated solutions to the problem.

Project-based learning is a student-driven, active learning experience where students perform constructive investigations. Learning activities are driven by a problem which results in a final product that addresses the problem. The activities are performed over a period of time and lecturers assume an advisory rather than an instructive role. Projects are central rather than peripheral to the curriculum (Thomas, 2000; Helström, Nilsson \& Olsson, 2009).

While case-based learning and PBL can be distinguished by the presence (or absence) of an active engagement with business enterprises, the difference between PBL and problembased learning is somewhat ambiguous. Many experienced PBL practitioners regard PBL as synonymous with problem-based learning (Alvarstein \& Johannesen, 2001; Hanney, 2005). Although Savin-Baden (2003) as cited by Hanney (2005:110) highlights some semantic differences, the most prominent feature that distinguishes PBL from problem-based learning is that PBL culminates in an artefact or end product such as a report to a 'client' (Danford, 2006; Helle et al., 2006).

Case studies on the implementation of the constructivist teaching and learning strategies in various disciplines have been well documented in the literature (for example Thomas, 2000; Fourie, Nieuwoudt \& Van Vuuren, 2003; Hanney, 2005; Danford, 2006; Garcia, 2006; Helle, Tynjälä \& Olkinoura, 2006; Hunaiti et al., 2010; Lee et al., 2010; Hallinger \& Lu, 2011). Most authors agree that the main aim of constructivist strategies is to move away from pure textbook teaching and 'talk and chalk strategies' to a combination of theory and practice to enhance the business skills of graduates. Various authors advocate the integration of research skills and practical skills involving industry (eds. Talaba \& Ten Thij, 2007). 
The results of a literature search on the implementation of constructivist teaching strategies in logistics specifically are limited. Alvarstein and Johannesen (2001), Gudmundsson and Nijhuis (2001), Van Hoek (2001), Pal and Busing (2008) and Lei Wang (2009) propagate either a case-based strategy, problem-based strategy or project-based strategy in the teaching and learning of logistics.

Although it is possible that constructivist strategies are being used in the teaching of Logistics Management at undergraduate level in South Africa, no evidence could be found in the literature to support such a possibility. Furthermore, most literature on PBL or problembased learning referred to above reports on fully fledged PBL or problem-based courses as opposed to applying the principles of these strategies as one element of the teaching strategy. In many instances the literature focuses on postgraduate studies. The literature search produced only the work by Van Hoek (2001) that incorporates research skills in the teaching strategy for undergraduate logistics students. This research aims to add to the body of knowledge on the implementation of teaching and learning strategies in Logistics Management on undergraduate level.

The integrated approach advocated in this paper is based on certain elements of PBL rather than problem-based learning or case-based learning. Considering the criteria for PBL discussed earlier the suggested approach is not a purely project-based strategy. Although it conforms to most criteria of PBL, it does not meet the criterion of centrality (i.e. projects are not central to the curriculum). The reason for this is that the approach focuses on teaching undergraduate courses where students require knowledge on a wider range of topics than what projects can offer. The suggested approach is clearly not a problem-based strategy because projects culminate into products (reports to clients). It is also not a casebased strategy because it involves real-life projects in collaboration with industry. Danford (2006:9) distinguishes case-based learning from PBL in that PBL 'mirrors that of the real business situation' and that learners are actively engaged with business enterprises on real projects. He concludes that PBL is a comprehensive instructional model in which project work is central to students' understanding of the essential concepts and principles of the discipline and that PBL is clearly focused on the end product.

To accommodate the development of students' research skills, the features of PBL were adapted to implicitly include research skills. Hence, the notion of integrated teaching and learning (ITL). ITL is aimed at the simultaneous development of business skills (applying theoretical principles to real-life practical situations), research skills (such as conducting a literature search and review, research design, collecting, analysing and interpreting information, compiling a report) and life skills incorporating CCFOs. The ITL approach follows the same process as a project-based strategy (setting the stage, defining the task, suggesting resources, identifying steps for the investigation, guidance to students, collaborative learning, reflection) as reported by Grant (2002). 
Alvarstein and Johannesen (2001) summarise the value of PBL (and for that matter, the integrated approach as suggested in this paper) as follows:

'One need not go any further than the employment ads in the newspaper to see similarities between skills learned by students through PBL and those skills wanted by future employees.'

\section{RESEARCH STRATEGY}

\section{Research approach}

This paper presents a case study of the integrated approach to teaching and learning logistics. The case study involved a pilot project where 42 Logistics Management students in their third (and final) year of undergraduate study at the North-West University (Mafikeng Campus) in South Africa were engaged in an external customer service audit at a major retailer in the FMCG industry. The aim of the project was to present a report to the retailer containing recommendations on specific customer service strategies with a view to enhancing the competitive advantage of the retailer. A detailed project plan guided the process where the lecturer acted partly as supervisor and partly as facilitator. Students were exposed to collaborative learning (team work), questionnaire design, conducting surveys, analysing and evaluating results, literature review and report writing. The project was rolled out in phases where students were assessed after each phase. On completion of the project, students were asked to complete a questionnaire anonymously to ascertain their perceived value of the project.

The results of the research are based on the assessment of the students during each phase of the project and the students' perception of the project. Conclusions and recommendations are made based on the results. (The results of the customer service project will be reported in a separate paper at a later stage.)

\section{Participants}

The participants in the study included all students (in total 42) registered for the particular module (course). Most students were school leavers with an average age of approximately 21 years. They had no or little exposure to practical research projects or real-life business problems.

Although it hosts some international students (mainly from other parts of Africa) the Mafikeng campus serves a relatively poor community with a predominantly rural character. The majority of the participants in the study are dependent on financial assistance (mainly from government). Although not confirmed by research, it is known that the socioeconomic circumstances of the majority of the students prevent them from having access to critical resources required for their studies. For example, students cannot afford their own computers and are dependent on the availability of computers in the computer laboratories 
on campus. Some of them even share textbooks. Hunaiti et al. (2010) argues that the diverse composition of the student population poses certain challenges to teaching and assessment methods. This is particularly true at the Mafikeng campus where the tuition language (English) is not the students' first language.

\section{Methods of data gathering}

The data gathered focuses on the assessment results of students after each phase of the project and on the students' perceptions of the project.

Continuous assessment was applied where students were assessed after each phase of the project (Helle et al., 2006; Hunaiti et al., 2010). Certain elements were assessed in group context while other elements were assessed individually (Alvarstein \& Johannesen, 2001; Fourie, Nieuwoudt \& Van Vuuren, 2003; Brumberger, 2004). Appropriate rubrics were used for the assessment based on the work by Anderson and Puckett (2003), Gülbahar and Tinmaz (2006) and Hunaiti et al. (2010). Suitable assessment criteria were formulated with due consideration of the level of the module (third year undergraduate, or in SAQA terms, NOF 7).

On completion of the project, students were asked to complete a questionnaire where they had to indicate on a 5-point Likert scale to what extent they agree with statements which focused on their learning experience and enhancement of business, research and life skills (1 indicating strongly disagree and 5 indicating strongly agree). The questionnaire also contained open-ended questions where students were invited to express their likes and dislikes of the project. To encourage honest answers, students remained anonymous.

\section{Procedure}

In accordance with PBL principles, a detailed project plan guided the process while the lecturer acted as facilitator and supervisor rather than instructor (Grant, 2002; Hanney, 2005). During the first contact session of the semester, students were asked to form teams through self-organisation (Van Hoek, 2001). The only provision was that the team size be limited to four individuals to prevent certain students from just 'going with the flow'. The literature reveals much controversy and debate on group size and dynamics. However most agree that the group size should be between two and six individuals (Fourie et al., 2003; Brumberger, 2004; Danford, 2006; Helle et al., 2006; Hellström et al., 2009; Lee et al., 2010). The criteria that seem to play a role in the size of teams are the extent of the project, the size of the class, the level of the course and the administrative burden on the lecturer to manage the project and teams.

The project was implemented in phases over a period of 11 weeks with deadlines for each phase as indicated in Table 1. Meeting deadlines was extremely important to finish the project before the end of the semester. 
Table 1: Project time frame and assessment

\begin{tabular}{|l|c|c|c|c|c|c|c|c|c|c|c|}
\hline & \multicolumn{9}{|c|}{ Weeks } \\
\hline Activity & $\mathbf{1}$ & $\mathbf{2}$ & $\mathbf{3}$ & $\mathbf{4}$ & $\mathbf{5}$ & $\mathbf{6}$ & $\mathbf{7}$ & $\mathbf{8}$ & $\mathbf{9}$ & $\mathbf{1 0}$ & $\mathbf{1 1}$ \\
\hline Literature search & 20 & & & & & & & & & & \\
\hline Select retailer & & & & & & & & & & & \\
\hline Provisional list & & 10 & & & & & & \multicolumn{3}{|c|}{ Individual (70) } \\
\hline Final list & & & & & & & & \multicolumn{3}{|c|}{ Group (80) } \\
\hline Design questionnaire & & & & 20 & & & & & & & \\
\hline Test questionnaire & & & & & & & & & & & \\
\hline Survey & & & & & & & 20 & & & & \\
\hline Capture results & & & & & & & & 10 & & & \\
\hline Analyse and report & & & & & & & & & & 20 & 50 \\
\hline
\end{tabular}

During the entire process, much emphasis was placed on the students' assessment results since many authors regard assessment involving teamwork as challenging. The major concern in this regard appears to be the fairness of assessment and the equal participation of all students (Fourie et al., 2003; Postholm, 2008; Hellström et al., 2009). Based on this concern, it is not surprising that Helle et al. (2006) highlight the particular interest of researchers, policy makers and teachers (who consider the implementation of PBL courses) in assessment strategies and results.

In this case study, students were assessed after each phase of the project. Certain activities were assessed in group context (80 out of 150 marks) while other activities were assessed individually (70 out of 150). This dual assessment approach was followed in an attempt to overcome some of the problems related to $\mathrm{PBL}$, particularly to encourage students to actively participate in the project and to increase the fairness of the assessment. The lecturer allocated weights and formulated assessment criteria for each phase based on his view of the importance of each phase. It has to be noted that the project served as a compulsory assignment, contributing only $10 \%$ to the final mark for the module. The current university policy on assessment for undergraduate modules places more emphasis on written tests as a formative assessment instrument and examinations as a summative assessment instrument.

The phases and the assessment of each phase are discussed in more detail below.

\section{Literature search}

At the start of the project, students were instructed to search for appropriate literature and to incorporate that literature into the final report. Although this activity was assessed individually, students were allowed (and indeed encouraged) to also use the literature found by other members in the group when compiling their individual reports. Since the project 
involved undergraduate students, the assessment criteria for this activity were quite lenient. Students were awarded $40 \%$ for merely attaching an article to their final report regardless of its quality. Another $40 \%$ was awarded if the article was useful for the report. The remaining $20 \%$ was earned if the article had been published in a reputable journal.

\section{Project and client selection}

As reported by Fourie et al. (2003) and Helle et al. (2006) finding appropriate projects is quite problematic. Helle et al. (2006) argues that simplicity, workload, students' capability and relevancy play, among other things, a significant role in project selection. Considering the socio-economic characteristics of the participants, the 'client' had to be in close proximity to the campus. This requirement limited the project to the retail stage of the supply chain. Students were given the option of selecting a manufacturer, but were warned about the logistical difficulties that could arise during the on-site survey. Consequently they opted for a retailer within walking distance of campus. Another problem was to identify a project that covers a reasonably significant part of the prescribed module curriculum. Customer service covers approximately $25 \%$ the curriculum. Having reached consensus on the specific retailer, the lecturer established contact with the retailer. The project plan was presented to the manager of the retail store who was very co-operative and indeed excited about the project.

\section{Provisional list of customer service attributes}

Teams had to compile a list of customer service attributes that they regarded as important to a retailer for inclusion in the customer service questionnaire. These were debated during a meeting between team representatives and the lecturer to reach consensus on which attributes to include in the questionnaire. The number of attributes had to be limited to save time during the survey phase. There were 12 groups and working with 12 sets of attributes and 12 different questionnaires would complicate the rest of the project. The teams had to do some research or apply their minds to find suitable customer service attributes. The assessment criteria for this activity comprised the applicability of the attributes to the retail environment (50\%) and its usefulness for the current project (30\%). The remaining $20 \%$ was awarded to the team if they provided at least 10 attributes.

\section{Finalisation of the list of service attributes}

Having reached consensus, the retailer was consulted to obtain his inputs to finalise the list of attributes. Continuous consultation with the 'client' cannot be overemphasised (Lee et al., 2010) and took place throughout the project.

\section{Design and testing of the questionnaire}

Once the customer service attributes were finalised, teams had to design a suitable questionnaire. Their brief was to use the information in the textbook and design a 
questionnaire that would provide data to measure the importance of each attribute to a customer as well as the customers' perception of conformance of the retailer and its major competitors to each attribute (on a scale of 1 to 7). They also had to include some demographic factors in the questionnaire. Assessment was based on the usefulness of the questionnaire and whether it contained clear instructions to the customer (30\%), logical layout (30\%), appropriate and clear customer service attributes listed (5\%), introduction to the customer (5\%), provision for an importance rating (10\%), provision for competitors' rating (10\%) and provision for demographic information (10\%). At the end of this phase, another meeting between the lecturer and team representatives was scheduled to finalise the questionnaire. The questionnaire was then tested among some fellow students and lecturers. Testing the questionnaire was not assessed due to the insignificance on the total project. Once again, the retailer was consulted for his input and consent.

\section{Conducting the survey}

To ensure sufficient response for a representative sample, an in-store survey was conducted after due consultation with the management of the store. During the week allocated for this activity, each team had to interview 40 customers (on average 10 per person) capturing the information on the questionnaire. Before the survey, students were coached on how to approach the customers, how to use the questionnaire and on their general conduct and appearance during the survey. The teams were assessed on the agreed number of questionnaires completed (20\%), completeness of the questionnaire (20\%), usefulness of the completed questionnaire (50\%) for the rest of the project and the general appearance, courtesy and attitude towards the customers (10\%). The latter criterion was evaluated through observation.

\section{Data capturing}

Each team had to capture the data from the questionnaires on Excel and calculate the average and standard deviation of the scores for the importance rating and the conformance to the attributes by each retailer (the client and its major competitors). Assessment criteria were accuracy (45\%), completeness (45\%) and meeting the deadline (10\%). Meeting the deadline in this phase was crucial because all teams' data capturing and statistical analysis had to be collated to create a single set of data representing all questionnaires for the class. The collation process was done by the lecturer first as part of the assessment of this phase and secondly to ensure accuracy of the final statistics. The collated data was distributed to each group for them to analyse.

\section{Data analysis}

Following the capturing phase, the collated data was analysed in groups, using methodology contained in the textbook prescribed for the module. Teams were assessed on constructing a competitive position matrix (50\%) and a performance evaluation matrix (50\%). 


\section{Final report}

Each individual student had to prepare a final report. This activity contributed $33.3 \%$ to the final mark for the project. Reports were assessed on the basis of a logical structure (10\%), using and referring to literature (20\%), using the competitive position matrix (25\%) and performance evaluation matrix (25\%) to formulate meaningful conclusions and recommendations (20\%) to the retailer. Obviously all individual reports were not submitted to the retailer. Only one report, collated by the lecturer, was submitted. However, individual reports were assessed as if they were presented to the retailer.

\section{DISCUSSION}

The results of the research focus first on the assessment of the students during each phase of the project and secondly on the how students perceived the approach in terms of their research, practical and life skills development.

\section{Assessment results}

The assessment of the project indicated that there are major shortcomings in the students' skills. However, there is also evidence of satisfactory skills in certain areas. The assessment results are summarised in Figure 1 which indicates the weight allocated to each activity and whether the activity was assessed in group context or individually.

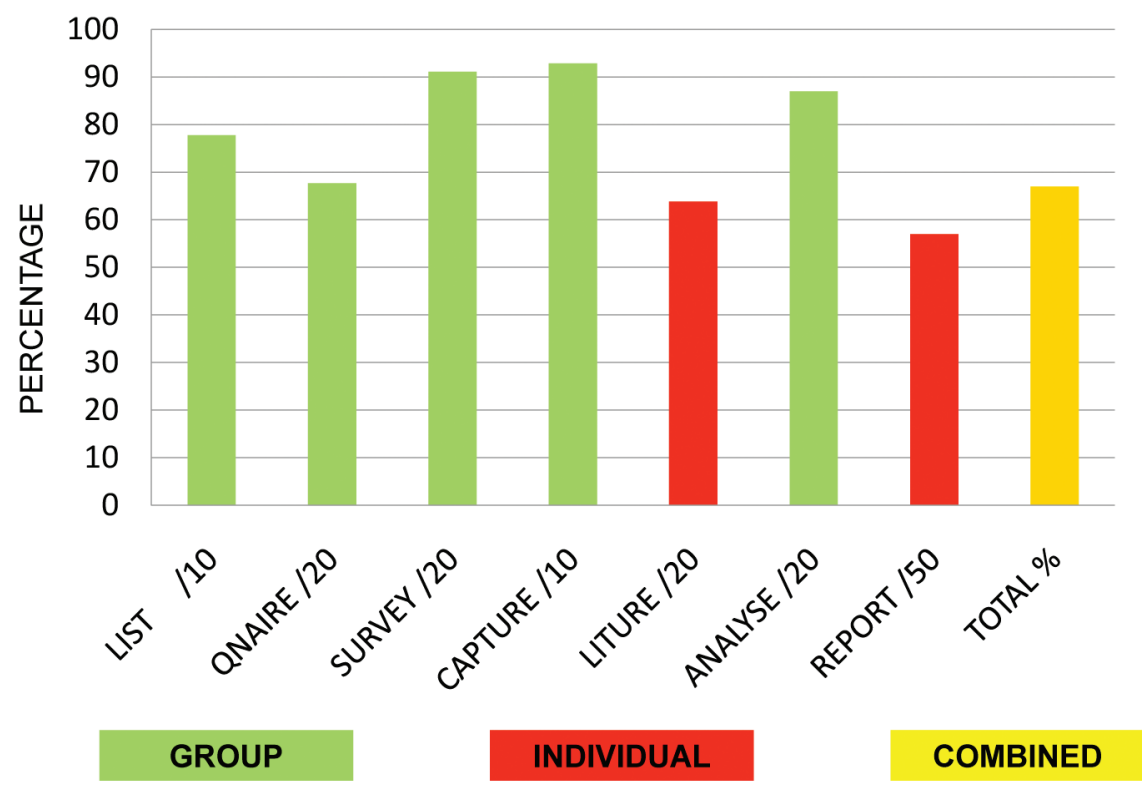

Figure 1: Assessment results (average)

It is evident from the assessment results that students performed better in group activities than in individual activities, which confirms that collaborative learning is a successful strategy in increasing the learning experience of students (Helle et al., 2006; Hellström et al., 2009). The assessment revealed that the students experienced problems with questionnaire 
design, finding suitable literature in reputable sources, interpreting data and writing a final report. On the positive side, one can conclude that students worked well in teams, they had a very positive attitude towards practical projects, they demonstrated patience and perseverance during the survey, they were able to capture results (with a little help from the lecturer) and they were quite able to analyse the results after some consultation with the lecturer and using methodology contained in the textbook.

\section{Student perceptions}

Similar to the approach followed by various authors (for example Brumberger, 2004; Gülbahar \& Tinmaz, 2006) a 5-point Likert scale was used with structured questions to ascertain the students' perceptions of the project

Thirty-nine out of the 42 questionnaires to students were returned. The results are shown in Figure 2, reflecting only the scores of 4 and 5 (indicating strong agreement with statements made in the questionnaire).

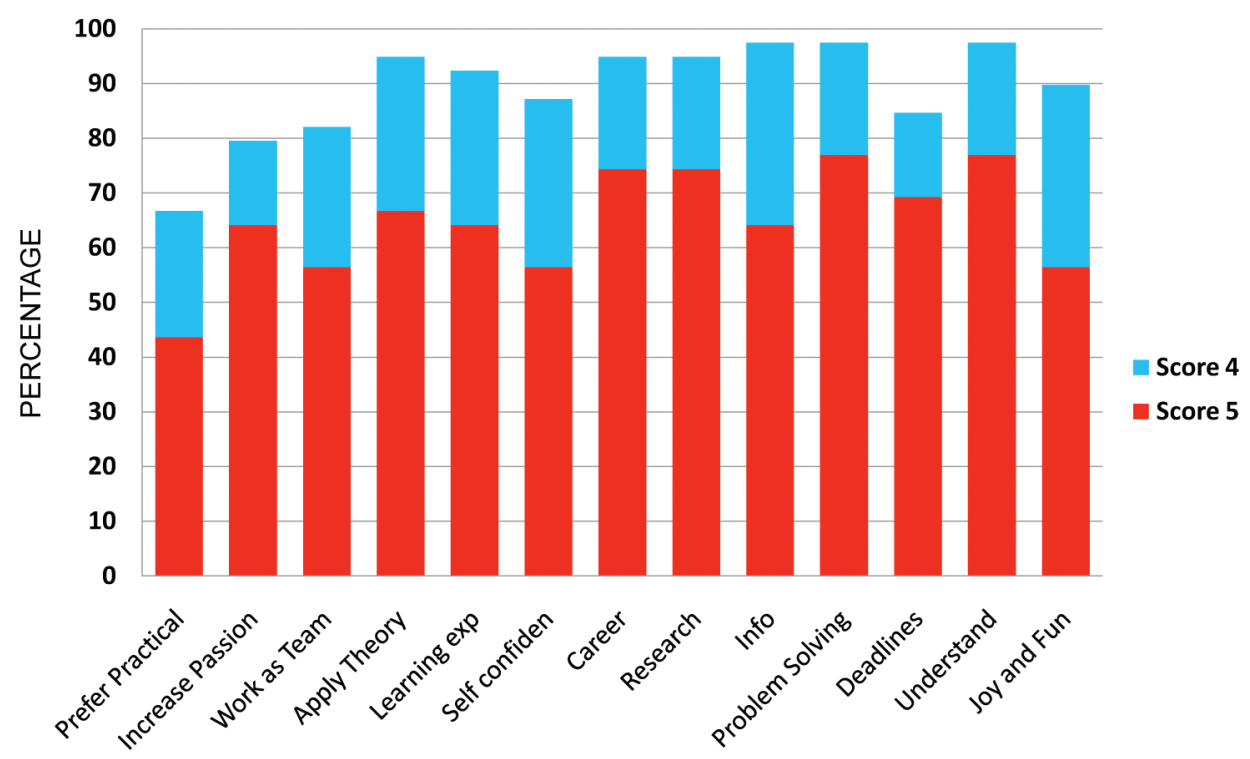

Figure 2: Student perceptions: Structured questions

The results show that the students prefer practical projects rather than purely theoretical and case study type of assignments (67\% of the students rated this statement as 4 or 5 , indicating that they strongly agree with the statement). Almost all students (95\%) felt that the project enhanced their research skills and business skills (as reflected in the question on applying theory). As far as life skills are concerned, 82\% perceived that the project helped them to work as part of a team, 87\% felt that the project increased their self-confidence and $97 \%$ agreed strongly that the project improved their skills to collect, organise and analyse information and to solve problems. Furthermore the results show that the project increased their passion for the subject (Logistics), widened their learning experience, was of great 
value in preparing them for a career, helped them understand the learning material on customer service audits more clearly and was even fun!

The open-ended questions revealed that the majority (54\%) of the students enjoyed the survey phase most (interviewing customers) although a few (15\%) indicated that they disliked it when customers gave them a cold shoulder. Many students (38\%) expressed their concern with the duration and workload associated with the project. This is understandable considering the relatively insignificant contribution to their final marks for the module (10\%) and the number of modules (on average five) that they study per semester. One can therefore conclude that future projects should either be less time consuming or contribute more to the final mark of the module. It is interesting to note that $10 \%$ of the students indicated that they liked teamwork the most while $13 \%$ indicated that they disliked this aspect of the project the most. Some students indicated orally after the project that team co-operation and disagreement among team members contributed vastly to the time used for the project. In the context of the ITL approach, disagreement among team members is not necessarily undesirable because in real life they will frequently be confronted with a similar phenomenon.

Although not recorded on the questionnaire, many students expressed their gratitude orally for being involved in a practical project.

\section{CONCLUSION}

This paper advocates an ITL approach based on the principles of a project-based teaching and learning strategy for undergraduate Logistics students.

Although a single pilot project for the ITL approach as presented in this paper does not provide sufficient evidence, the impact on learning could be quite significant. There is little doubt that such an approach enhances higher order thinking skills, business skills, research skills and life skills of undergraduate students (Alvarstein \& Johannesen, 2001; Van Hoek, 2001; Gülbahar \& Tinmaz, 2006; Hellström et al., 2009; Hunaiti et al., 2010). Only time will tell whether it will, in fact, facilitate the task of senior academic staff in supervising research projects or dissertations on postgraduate level.

While the implementation of an ITL approach is fairly easy in classes with a small number of students, it may be more complicated and time consuming in larger classes due to the co-ordination and assessment required for the process. However, such problems may be overcome by assigning different roles to different teams. For example, one or two teams could fulfil a co-ordinating role (Van Hoek, 2001). In addition, peer assessment or selfassessment strategies could be considered (Brumberger, 2004; Helle et al., 2006; Helström et al., 2009; Hunaiti et al., 2010). 
Based on the lecturer's observation during the project and the students' responses to the open-ended questions, it is recommended that future projects should be less time consuming or should contribute more to the final mark of the module.

Workshops or training sessions should be arranged to assist students in conducting a literature search and review, to interpret information and to enhance their writing skills. Rutledge and Maehler (2003) report on a case study where library education sessions significantly improved the research skills of undergraduate students. The Academic Development Centre, established at the North West University to provide academic support services, can be utilised to conduct training sessions on writing skills. Alternatively, more intensive lecturer supervision is required during the final phases of projects. However, this will be even more time consuming for both students and lecturers, particularly in larger classes. Furthermore, since the government subsidy for undergraduate studies is considerably less than for postgraduate studies, lecturers are expected to spend more time on postgraduate supervision.

Future research on the topic could include the implementation of the ITL approach in larger classes and the extent of the application of PBL or variants thereof in undergraduate Logistics courses, particularly in South Africa. Another research opportunity in the years to come would be to ascertain (either through qualitative, quantitative or mixed research methods among businesses and senior academics) to what extent the ITL approach enhances the practical business skills, employability and research skills of students. 


\section{REFERENCES}

Anderson, R.S. \& Puckett, J.B. 2003. Assessing students' problem-solving assignments. Problem-based learning in the information age. New directions for teaching and learning. 95(Fall 2003):81-87.

Alvarstein, V. \& Johannesen, L.K. 2001. Problem-based learning approach in teaching lower level logistics and transportation. International Journal of Physical Distribution \& Logistics Management. 31(7/8):557-73.

Bender, C.J.G., Daniels, P., Lazarus, J., Naude, L. \& Sattar, K. 2006. Service learning in the curriculum: A resource for higher education institutions. Pretoria: Council on Higher Education.

Brumberger, E.R. 2004. The 'corporate correspondence project': Fostering audience awareness and extended collaboration. Business Communication Quarterly. 67(3):349-58.

Danford, G.L. 2006. Project-based learning in international business education. Journal of Teaching in International Business. 18(1):7-25.

Fourie, P. duT, Nieuwoudt, I. \& Van Vuuren, J.H. 2003. Methods of OR: a new graduate course. Orion. 19(1/2):1-31.

Garcia, A. 2006. Combining professional development with academic learning in graduate seminars. Radical Pedagogy: International consortium for the advancement of academic publication, 8 (2). Available from: http://redicalpedagogy.icaap.org/content/issue8-2/ garcia.html (Accessed 26 May 2011).

Gattorna, J. 2009. Dynamic supply chain alignment: a new business model for peak performance in enterprise supply chains across all geographies. Farnham, Surrey: Gower.

Grant, M.A. 2002. Getting a grip on project-based learning: theory, cases and recommendations. Meridian: A Middle School Computer Technologies Journal, 5 (1). Available from: http://www.ncsu.edu/meridian/win2002/514 (Accessed 27 May 2011).

Gudmundsson, S.V. \& Nijhuis, J. 2001. Collaborative learning in logistics and transport: The application of 3WIM. International Journal of Physical Distribution \& Logistics Management. 31(7/8):537-56.

Gülbahar, Y. \& Tinmaz, H. 2006. Implementing project-based learning and e-portfolio assessment in an undergraduate course. Journal of Research and on Technology in Education. 38(3):309-27. 
Hallinger, P. \& Lu, J. 2011. Implementing problem-based learning in higher education in Asia: Challenges, strategies and effect. Journal of Higher Education Policy and Management. 33(3):267-85.

Hanney, R. 2005. Competence or capability: Work-based learning and problem-based learning. Journal of Media Practice. 6(2):105-12.

Helle, L., Tynjälä, P. \& Olkinoura, E. 2006. Project-based learning in post-secondary education: Theory, practice and rubber sling shots. Higher Education. 51:287-314.

Hellström, D., Nilsson, F. \& Olsson, A. 2009. Group assessment challenges in project-based learning: Perceptions from students in higher engineering courses. Utvecklingskonferensen för Sveriges ingenjörsutbildningar, LTH 2-3 December 2009. Available from: http://www. Ith.se/fileadmin/lth/genombrottet/natutvkonferens2009/proceedings/46Hellstrom_etal. pdf (Accessed 22 August 2011)

Hunaiti, Z., Grimaldi, S., Goven, D., Mootanah, M. \& Martin, L. 2010. Principles of assessment for project and research based learning. International Journal of Educational Management. 24(3):189-203.

Lee, G., McGuiggan, R. \& Holland, B. 2010. Balancing student learning and commercial outcomes in the workplace. Higher Education Research and Development. 29(5):561-74.

Lei Wang, B.O. 2009. To explore teaching mode of logistics system simulation. First international workshop on educational technology and computer science. Education Technology and Computer Science. 1:317-19.

Pal, R. \& Busing, M.E. 2008. Teaching operations management in an integrated format: student perception and faculty experience. International Journal of Production Economics. 115:594-610.

Postholm, M.B. 2008. Group work as a learning situation: a qualitative study in a university classroom. Teachers and Teaching: theory and practice. 14(2):143-55.

Republic of South Africa. 1998. Regulations for national standards bodies. Government Gazette No 18787. Pretoria: Government Printers.

Republic of South Africa. 2007. The Higher Education Qualifications Framework. Government Gazette No.30353. Pretoria: Government Printers. 
Rutledge, D.P. \& Maehler, A. 2003. An assessment of library education contributions to business student learning: A case study. Journal of Business \& Finance Librarianship. 9(1):3-19.

Talaba, D, \& ten Thij, H. (Eds). 2007. Teaching and research synergy in the context of university-industry cooperation. Special interest group 3 of the European University - Industry Network (EUI-Net): Guidelines and best practices in Europe teaching - research synergies. Brasov-Eindhoven. Available from: http://ier-nl.net/Teaching_and_Research_Synergy_prefinal.pdf (Accessed 26 May 2011).

Thomas, J.W. 2000. A review of research on project-based learning. Available from: http:// www.bie.org/research/study/review_of_project_based_learning_2000 (Accessed 23 May 2011).

Van Hoek, R.I. 2001. Logistics education: achieving market and research driven skill development. International Journal of Physical Distribution and Logistics Management. 31(7/8):505-19.

Table of acronyms

\begin{tabular}{|l|l|}
\hline CCFO & Critical Cross Field Outcomes \\
\hline FMCG & Fast Moving Consumer Goods \\
\hline HEQF & Higher Education Qualifications Framework \\
\hline ITL & Integrated Teaching and Learning \\
\hline NQF & National Qualifications Framework \\
\hline PBL & Project-Based Learning \\
\hline SAQA & South African Qualifications Authority \\
\hline
\end{tabular}

